\title{
Influence of Irrigation Scheduling on Fruit Quality of Young Potted 'Manzanilla de Sevilla' Olive Trees
}

\author{
A. Morales-Sillero \\ Universidad de Sevilla \\ 41013-Sevilla \\ Spain
}

\author{
J.E. Fernández, J.M. Torres-Ruiz and \\ A. Montero \\ Instituto de Recursos Naturales y \\ Agrobiología (IRNAS-CSIC) \\ Avenida de Reina Mercedes, 10 \\ 41012-Sevilla \\ Spain
}

Keywords: Olea europaea L., mesocarp, endocarp, oil content

\begin{abstract}
The aim of this work was to analyse the influence of soil water content and distribution on fruit quality in 5-year-old 'Manzanilla de Sevilla' olive trees in pots subjected to different irrigation treatments for 3 years (2007-2009). The experiment was carried out near Seville, in southwest Spain. Four water treatments were considered: 1) T0, trees were under dry farming conditions except for small amounts of water supplied to ensure their survival; 2) T1, irrigation dose was about $50 \%$ of the crop's water needs $\left.\left(E T_{c}\right) ; 3\right) \mathrm{T} 2$, irrigated at $100 \%$ of $E T_{c}$. Some of the roots of the T1 and T2 trees were left in drying soil during the irrigation season; 4) T3, irrigated to non-limiting soil water conditions in the whole rhizosphere throughout the irrigation season. All treatments were fertilized under non-limiting conditions. Results from the 2009 season showed no differences between treatments in either fruit or endocarp shapes. In all cases, the longitudinal diameters of both fruits and endocarps increased with the amount of water applied, as did equatorial diameters, except without significant differences between irrigation treatments. Fruit weight, volume and the mesocarp/endocarp ratio also increased with the amount of water applied. Those increments were mainly related to those of fresh and dry mesocarp weights. The endocarp weight, both fresh and dry, was lower in T0 than in the irrigation treatments, with no differences between irrigation treatments. Oil content on a fresh weight basis decreased significantly with the amount of irrigation and no differences between T2 and T3 were found. These results show both a positive response of fruit quality to regulated deficit irrigation and the fact that wetting the whole rhizosphere to around field capacity influences little, if any, the fruit quality.
\end{abstract}

\section{INTRODUCTION}

The olive tree (Olea europaea L.) is well adapted to dry conditions, which are usual in areas in which it is cropped. Water supplied during the dry season, however, improves olive yield, fruit weight, volume, mesocarp/endocarp ratio and oil yield, among others parameters related to table olive and oil quality (Lavee and Wodner, 1991; Patumi et al., 2002; Moriana et al., 2003). Not only amount, but also distribution of the water in the soil is important. There is evidence to suggest that olive tree transpiration is markedly increased when water supplied by irrigation wets the whole rhizosphere (Fernández et al., 2003). There is a lack of information, however, on the influence of water distribution in the soil on fruit quality and oil content.

The aim of this work was to analyse the extent to which fruit quality in 5-year-old 'Manzanilla de Sevilla' olive trees is modified by soil water content and distribution.

\section{MATERIALS AND METHODS}

The experiment was carried out at 'La Hampa' experimental farm, close to Coria del Río, Seville, in southwest Spain ( $37^{\circ} 17^{\prime}$ N, $6^{\circ} 3^{\prime}$ W), in 2009. In 2007, when the trees were 3 years old, a completely randomized design with 3 trees per plot and 4 plots per treatment was established. Each tree was planted in the middle of two 50-L pots, with 
about half of the root system in each pot. The growing media was sandy loam soil (14.8\% clay, $7.0 \%$ silt, $4.7 \%$ fine sand and $73.5 \%$ coarse sand). Drainage was favoured by a 0.05 $\mathrm{m}$ gravel layer at the bottom of the pots. Four water treatments were considered: 1) dry farming conditions, except for small amounts of water supplied to ensure the survival of the trees (treatment T0); 2) regulated deficit irrigation in which the irrigation dose varied between $100 \%$ and $30 \%$ of the crop's water needs $\left(\mathrm{ET}_{\mathrm{c}}\right)$, depending on phenological stage (treatment T1); 3) daily irrigation with $100 \%$ of $\mathrm{ET}_{\mathrm{c}}$ (treatment T2); 4) pond irrigation, in which the whole rhizosphere was wetted to around field capacity throughout the irrigation season (treatment T4). Each irrigation season, the T1 trees received a total of ca 50\% of $\mathrm{ET}_{\mathrm{c}}$. In the T1 and T2 trees, some of the roots were left in drying soil during the irrigation season, to emulate the local irrigation systems normally used in olive orchards. The T0 and T3 trees had three $2 \mathrm{~L} / \mathrm{h}$ drippers per pot. The T2 and T1 trees had three drippers in one pot, and just one dripper in the other, to ensure that part of the root system would be left in drying soil during the irrigation season. The T1, T2 and T3 trees were irrigated daily from May to September. Irrigation doses were calculated by the crop coefficient approach, as described by Fernández et al. (2006). Basically, $\mathrm{ET}_{\mathrm{c}}$ was calculated as $\mathrm{ET}_{\mathrm{c}}=$ $K_{\mathrm{c}} K_{\mathrm{r}} \mathrm{ET}_{\mathrm{o}}$, with crop coefficient $\left(K_{\mathrm{c}}\right)$ values of 0.76 in May, 0.70 in June, 0.63 in July and August, 0.72 in September and 0.77 in October. The coefficient related to the percentage of ground covered by the crop $\left(K_{\mathrm{r}}\right)$ was 0.71 . In the 2009 season, when trees were 5 years old, the irrigation amounts were $176.8 \mathrm{~L} /$ tree in T0, 341.6 L/tree in T1, $650 \mathrm{~L} /$ tree in T2 and $1189.8 \mathrm{~L} /$ tree in T3.

In 2009, volumetric soil water contents $\left(\theta_{\mathrm{v}}\right)$ were measured every 7 to 10 days with a time domain reflectrometry (TDR) system (FOM, Institute of Agrophysics, Lublin, Poland), consisting of two $0.15 \mathrm{~m}$ long TDR probes inserted in each of the two pots of one tree peer plot, at the depths of at 0.05 and $0.20 \mathrm{~m}$.

The canopy volume of each tree was calculated in May (at the beginning of the irrigation period), from the measurements of the two perpendicular diameters at the height of maximum canopy width, plus the canopy height.

A fruit sample of $200 \mathrm{~g}$ per plot was picked on 3 September, at maturity index 1 (Beltrán et al., 2004), as is common with olives picked for 'Spanish-style' green processing. The average fruit weight, volume, mesocarp/endocarp ratio (calculated as the difference between fruit and mesocarp weight) and average fresh and dry weights both of the mesocarp and endocarp were determined. Fruit and endocarp shapes were calculated from measurements of the major longitudinal and equatorial diameters in 50 fruits per plot.

The harvesting was performed by hand on 14 October, when the maturity index was about 3.5. The number of fruits per tree was determined, and the oil content in fruits of each treatment was extracted and analysed by the standard Soxhlet method (UNE 55030).

Analyses of variance were performed on the data to evaluate differences among treatments. Separation of the means was obtained by least significant difference (LSD) test at the $0.05 \%$ probability level.

\section{RESULTS AND DISCUSSION}

Canopy volume at the beginning of the irrigation period was similar for T0 (the dryfarming treatment) and T1 (the regulated deficit-irrigation treatment), but increased significantly for T2 (daily irrigation with 100\% $\mathrm{ET}_{\mathrm{C}}$ ) and $\mathrm{T} 3$ (the pond irrigation treatment) (Table 1).

No differences between treatments were found in the number of fruits per tree. This result may have been influenced by a rainfall event of $14 \mathrm{~mm}$ that occurred at full bloom, which might have affected flowering and fruit set.

Other parameters related to fruit quality were, however, modified by the water treatments. Thus, fruit weight, volume and the mesocarp/endocarp ratio increased significantly in T2 as compared to T0 (Fig. 1). These increases were related specifically to those of the mesocarp and endocarp tissues. Table 1 shows, in fact, that both the fresh and 
dry weights of both tissues were greater in $\mathrm{T} 2$ than in $\mathrm{T} 0$. There were also differences in the longitudinal and equatorial diameters, although fruit and endocarp shapes were not affected. These findings confirm results previously published by d'Andria et al. (2009), although they also found that irrigation increases fruit number and yield.

However, the significant decrease in the amount of water applied in T1 as compared to T2 (ca. 50 vs. $100 \%$ of $\mathrm{ET}_{\mathrm{c}}$, respectively) had little effect on fruit weight, volume or mesocarp/endocarp ratio (Fig. 1). These variables were influenced by the decreases in fresh and dry weight of the mesocarp, as well as in the longitudinal diameters of the mesocarp and endocarp tissues (Table 1). The good response of the olive tree to regulated deficit irrigation has been observed previously by Magliulo et al. (2003), Lavee et al. (2007) and d'Andria et al. (2009), among others. This suggests that the application of regulated deficit irrigation in olive orchards in arid and semi-arid areas could significantly improve fruit quality. Results from the T2 and T3 trees showed that wetting the whole root zone has no effect on the studied variables. Caution must be taken, however, before extrapolating this result to mature trees under field conditions, since the performance of the studied trees could have been affected by the experimental conditions.

Oil content decreased significantly with the amount of irrigation, being about $24 \%$ lower in T1 and 45\% lower in T2 than in the dryfarming treatment (T0). Oil content was also significantly affected on a dry weight basis (data not shown), being lower in T2 and T3 than in T0 and T1. Again, no differences in oil content were found between T2 and T3. Our results agree with those of Lavee and Wodner (1991), who reported that application of irrigation usually causes an increase in fruit yield and oil yield, but a decrease in oil content. However, in others studies, no differences in oil content, expressed as \% fresh or dry weight, were found when different irrigation regimes were supplied (Motilva et al., 2000; Patumi et al., 2002; Magliulo et al., 2003; Tognetti et al., 2007). A possible explanation for this discrepancy is that the response of oil content to irrigation may be cultivar-dependent, as suggested by Lavee et al. (2007).

\section{CONCLUSIONS}

Results showed an increase in fruit weight with irrigation. This increase was related specifically to those of fresh and dry mesocarp tissue. Although fruit longitudinal and equatorial diameters increased with irrigation, fruit shape was not modified. The studied variables were little affected by a regulated deficit irrigation in which $50 \%$ of $\mathrm{ET}_{\mathrm{c}}$ was applied. However, for the experimental conditions (young plants in pots), wetting the whole rhizosphere to around field capacity did not seem to cause a different response in fruit quality relative to localized irrigation at $100 \% \mathrm{ET}_{\mathrm{c}}$. The extrapolation of this conclusion to mature trees growing in the field requires further study.

\section{ACKNOWLEDGEMENTS}

This work was funded by the Spanish Ministry of Education and Science, research project No.AGL2006-04666/AGR, and by the EU, research project ref. STREP 023120.

\section{Literature Cited}

Asociación Española de Normalización y Certificación. 1973. Spanish Standard UNE 55030.

Beltrán, G., Uceda, M., Hermoso, M. and Frías, L. 2004. Maduración. p.159-183. In: D. Barranco, R. Fernández-Escobar and L. Rallo (eds.), El cultivo del olivo. Mundiprensa, Madrid.

d’Andria, R., Lavini, A., Morelli, G., Sebastiani, L. and Tognetti, R. 2009. Physiological and productive responses of Olea europaea L. cultivars Frantoio and Leccino to a regulated deficit irrigation regime. Plant Biosystems 143:222-231.

Fernández, J.E., Díaz-Espejo, A., Infante, J.M., Durán, P., Palomo, M.J., Chamorro, V., Girón, I.F. and Villagarcía, L. 2006. Water relations and gas exchange in olive trees under regulated deficit irrigation and partial rootzone drying. Plant Soil 284:273-291. 
Fernández, J.E., Palomo, M.J., Díaz-Espejo, A. and Girón, I.F. 2003. Influence of partial soil wetting on water relation parameters of the olive tree. Agronomie 23:545-552.

Lavee, S., Hanoch, E., Wodner, M. and Abramowitch, H. 2007. The effect of predetermined deficit irrigation on the performance of cv. Muhasan olives (Olea europaea L.) in the eastern coastal plain of Israel. Scientia Hort. 112:156-163.

Lavee, S. and Wodner, M. 1991. The effect of yield, harvest time and fruit size on the oil content in fruits of irrigated olive trees (Olea europaea L.) cvs. Barnea and Manzanillo. Scientia Hort. 99:267-277.

Magliulo, V., d'Andria, R., Lavini, A., Morelli, G. and Patumi, M. 2003. Yield and quality of two rainfed olive cultivars following shifting to irrigation. J. Hort. Sci. Biotechnol. 78:15-23.

Moriana, A., Orgaz, F., Pastor, M. and Fereres, E. 2003. Yield responses of mature olive orchard to water deficits. J. Amer. Soc. Hort. Sci. 123:425-431.

Motilva, M.J., Tovar M.J., Romero M.P., Alegre S. and Girona J. 2000. Influence of regulated deficit irrigation strategies applied to olive trees (Arbequina cultivar) on oil yield and oil composition during the fruit ripening period. J. Sci. Food Agri. 80:20372043.

Patumi, M., d’Andria, R., Marsilio, V., Fontanazza, G., Morelli, G. and Lanza, B. 2002. Olive and oil quality after intensive monocone olive growing (Olea europaea L. cv. Kalamata) in different irrigation regimes. Food Chem. 77:27-34.

Tognetti, R., d'Andria, R., Sacchi, R., Lavini, A., Morelli, G. and Alvino, A. 2007. Deficit irrigation affects seasonal changes in leaf physiology and oil quality of Olea europaea (cultivar Frantoio and Leccino). Ann. Appl. Biol. 150:169-186. 


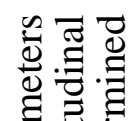

噌品

뜨흠

要骂

플

वे

可

중을

흔

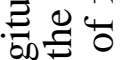

ㅎ..

둥

.00 든

3 을

동

宇

焉

혼 웜

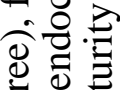

嗐

障演

运记䒕

o

叫

늠

믕

言

政券

문

政

종면

年

正:

응

त

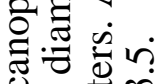

$-\dot{\square}$

함동

可. 3

둥 중

$>\dot{0} \cdot \overline{0}$

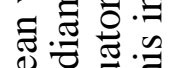

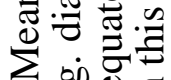

啳

\begin{tabular}{|c|c|c|}
\hline 言 & 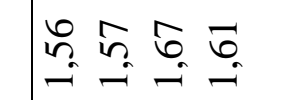 & $\cong$ \\
\hline & 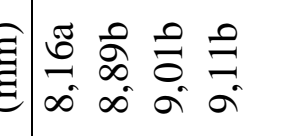 & \\
\hline & 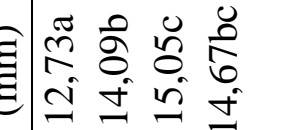 & 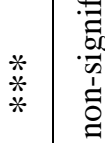 \\
\hline & | & \\
\hline & 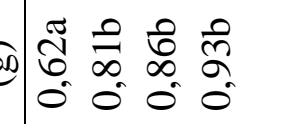 & $\begin{array}{ll}* \\
* \\
*\end{array}$ \\
\hline & 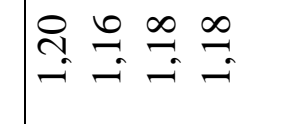 & $=\mid \begin{array}{l}\overline{0} \\
\dot{\nabla} \\
\vdots\end{array}$ \\
\hline & 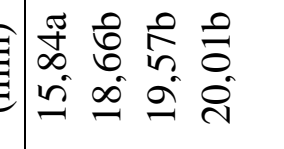 & \\
\hline & 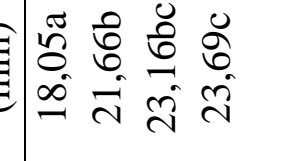 & \\
\hline & $\hat{a}$ & \\
\hline & 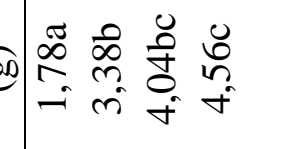 & \\
\hline 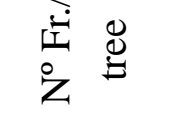 & $\stackrel{\infty}{\sim} \stackrel{n}{\sim} \vec{\beth} \vec{J}$ & \\
\hline & 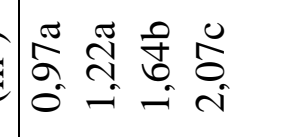 & \\
\hline 芯 & & : \\
\hline
\end{tabular}



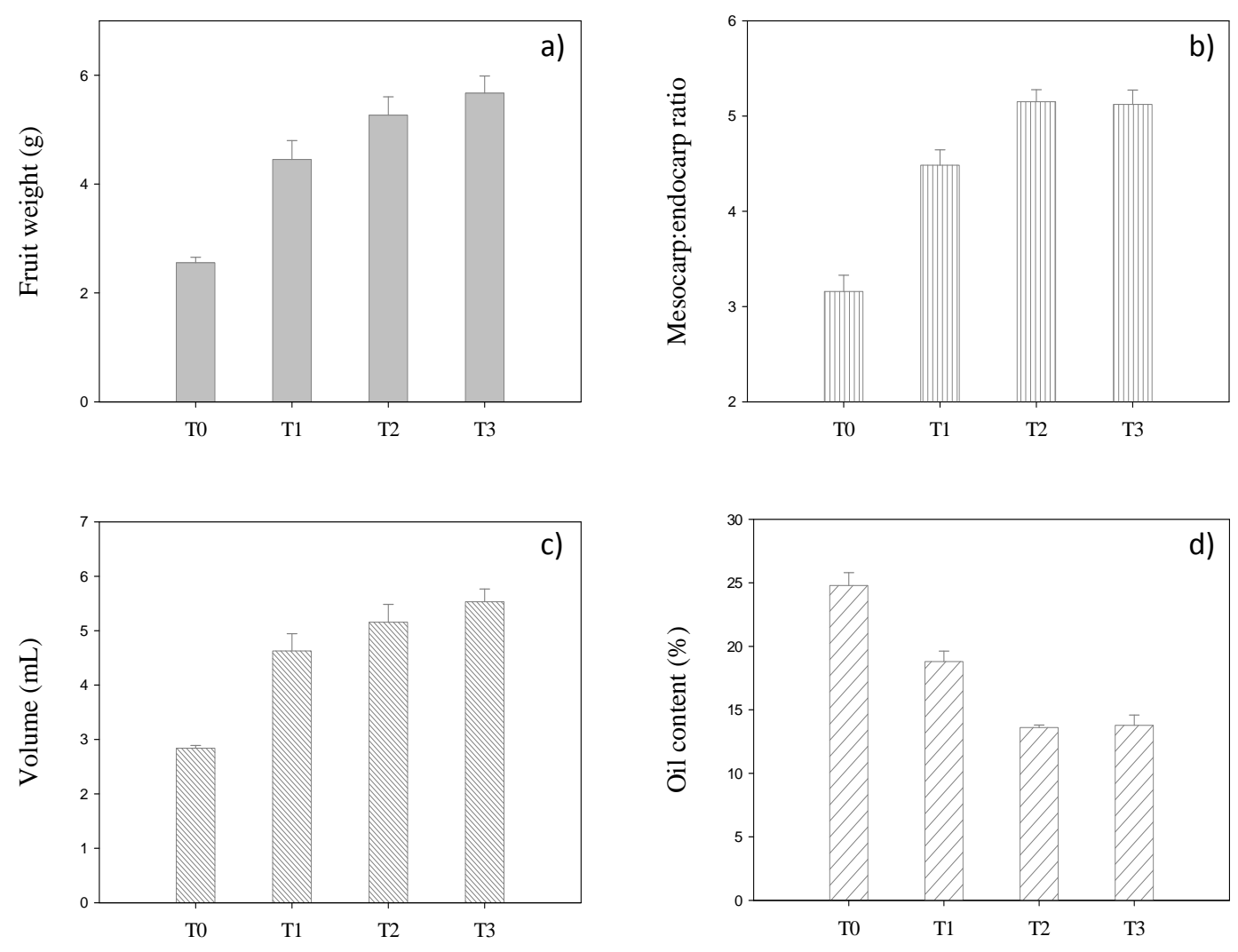

Fig. 1. Mean values of fruit weight, mesocarp/endocarp ratio, fruit volume, and oil content expressed on a fresh weight basis $(n=4 \pm S E)$. All fruit parameters were measured at a maturity index of 1; oil content was analysed when this index was 3.5. 